\title{
BMJ Open Ultra-processed foods and added sugars in the US diet: evidence from a nationally representative cross-sectional study
}

\author{
Eurídice Martínez Steele, ${ }^{1,2}$ Larissa Galastri Baraldi, ${ }^{1,2}$ \\ Maria Laura da Costa Louzada, ${ }^{1,2}$ Jean-Claude Moubarac, ${ }^{2}$ \\ Dariush Mozaffarian, ${ }^{3}$ Carlos Augusto Monteiro ${ }^{1,2}$
}

To cite: Martínez Steele E, Baraldi LG,

Louzada $\mathrm{M} L$ da $\mathrm{C}$, et al. Ultra-processed foods and added sugars in the US diet: evidence from a nationally representative cross-sectional study. BMJ Open 2016;6: e009892. doi:10.1136/ bmjopen-2015-009892

- Prepublication history and additional material is available. To view please visit the journal (http://dx.doi.org/ 10.1136/bmjopen-2015009892).

Received 3 September 2015 Revised 29 October 2015 Accepted 11 November 2015

\section{(a) CrossMark}

${ }^{1}$ Department of Nutrition, School of Public Health, University of São Paulo, São Paulo, Brazil

${ }^{2}$ Center for Epidemiological Studies in Health and Nutrition, University of São Paulo, São Paulo, Brazil

${ }^{3}$ Friedman School of Nutrition Science and Policy, Tufts University, Boston, Massachusetts, USA

Correspondence to Dr Carlos Augusto Monteiro; carlosam@usp.br

\section{ABSTRACT}

Objectives: To investigate the contribution of ultraprocessed foods to the intake of added sugars in the USA. Ultra-processed foods were defined as industrial formulations which, besides salt, sugar, oils and fats, include substances not used in culinary preparations, in particular additives used to imitate sensorial qualities of minimally processed foods and their culinary preparations.

Design: Cross-sectional study.

Setting: National Health and Nutrition Examination Survey 2009-2010.

Participants: We evaluated 9317 participants aged $1+$ years with at least one $24 \mathrm{~h}$ dietary recall.

Main outcome measures: Average dietary content of added sugars and proportion of individuals consuming more than $10 \%$ of total energy from added sugars.

Data analysis: Gaussian and Poisson regressions estimated the association between consumption of ultra-processed foods and intake of added sugars. All models incorporated survey sample weights and adjusted for age, sex, race/ethnicity, family income and educational attainment.

Results: Ultra-processed foods comprised $57.9 \%$ of energy intake, and contributed $89.7 \%$ of the energy intake from added sugars. The content of added sugars in ultra-processed foods $(21.1 \%$ of calories) was eightfold higher than in processed foods $(2.4 \%)$ and fivefold higher than in unprocessed or minimally processed foods and processed culinary ingredients grouped together $(3.7 \%)$. Both in unadjusted and adjusted models, each increase of 5 percentage points in proportional energy intake from ultra-processed foods increased the proportional energy intake from added sugars by 1 percentage point. Consumption of added sugars increased linearly across quintiles of ultra-processed food consumption: from $7.5 \%$ of total energy in the lowest quintile to $19.5 \%$ in the highest. A total of $82.1 \%$ of Americans in the highest quintile exceeded the recommended limit of $10 \%$ energy from added sugars, compared with $26.4 \%$ in the lowest.

\section{Strengths and limitations of this study}

- Use of a large, nationally representative sample of the US population, increasing generalisability.

- Use of data on added sugars rather than total sugars or sugar-sweetened beverages, which correspond to the guidelines relevant area of prioritisation.

- Unlike most articles which have focused on specific food items such as soft drinks or fast food, our study evaluates the impact of a comprehensive group of products whose consumption is increasing exponentially in most countries.

- Dietary data obtained by $24 \mathrm{~h}$ recalls are subject to potential error and bias.

- Information indicative of food processing is not consistently determined for all food items in National Health and Nutrition Examination Survey, which could lead to modest overestimation or underestimation of the consumption of ultra-processed foods.

Conclusions: Decreasing the consumption of ultraprocessed foods could be an effective way of reducing the excessive intake of added sugars in the USA.

\section{INTRODUCTION}

Increasing policy attention has focused on added sugars, including by the $\mathrm{WHO},{ }^{1}$ the UK National Health System, ${ }^{2}$ the Canadian Heart and Stroke Foundation, ${ }^{3}$ the American Heart Association (AHA) ${ }^{4}$ and the US Dietary Guidelines Advisory Committee (USDGAC). ${ }^{5}$

These reports concluded that a high intake of added sugars increases the risk of weight gain, ${ }^{1} 4{ }^{5}$ excess body weight ${ }^{5}$ and obesity ${ }^{35}$ type 2 diabetes mellitus; $;^{35}$ higher serum triglycerides $^{5}$ and high blood 
cholesterol $;{ }^{3}$ higher blood pressure ${ }^{5}$ and hypertension; ${ }^{5}$ stroke $;{ }^{3}{ }^{5}$ coronary heart disease $;^{35}$ cancer; ${ }^{3}$ and dental caries. ${ }^{1}{ }^{3} 5$ Moreover, foods higher in added sugars are often a source of empty calories with minimum essential nutrients or dietary fibre, ${ }^{6-8}$ which displace more nutrient-dense foods ${ }^{9}$ and lead, in turn, to simultaneously overfed and undernourished individuals.

All reports recommended limiting intake of added sugars. ${ }^{1}{ }^{3-5}$ In the USA, the USDGAC recommended limiting added sugars to no more than $10 \%$ of total calories. This is a challenge, as recent consumption of added sugars in the USA amounted to almost $15 \%$ of total calories in 2005-2010. ${ }^{1011}$

To design and implement effective measures to reduce added sugars, their dietary sources must be clearly identified. Added sugars can be consumed either as ingredients of dishes or drinks prepared from scratch by consumers or a cook, or as ingredients of food products manufactured by the food industry. According to market disappearance data from 2014, more than threequarters of the sugar and high fructose corn syrup available for human consumption in the USA were used by the food industry. ${ }^{12}$ This suggests that food products manufactured by the industry could have an important role in the excess added sugars consumption in the USA. However, to assess this role, it is essential to consider the contribution of manufactured food products to both total energy intake and the energy intake from added sugars, and, more relevantly, to quantify the relationship between their consumption and the total dietary content of added sugars. To address these questions, we performed an investigation utilising the 20092010 National Health and Nutrition Examination Survey (NHANES).

\section{SUBJECTS AND METHODS}

\section{Data source, population and sampling}

We utilised nationally representative data from the 20092010 NHANES, specifically the dietary component What we eat in America (WWEIA). ${ }^{13}$

NHANES is a continuous, nationally representative, cross-sectional survey of the non-institutionalised, civilian US residents. ${ }^{14}$ The NHANES sample was obtained by using a complex, stratified, multistage probability cluster sampling design based on the selection of counties, blocks, households and the number of people within households. ${ }^{14}$ In order to improve the estimate precision and reliability, NHANES 2009-2010 oversampled the following subgroups: Hispanic, Non-Hispanic black, Non-Hispanic white and Other persons at or below $130 \%$ of the federal poverty level and Non-Hispanic white and Other persons aged $80+$ years. ${ }^{14}$

The survey included an interview conducted in the home and a subsequent health examination performed at a mobile examination centre (MEC). All NHANES examinees were eligible for two $24 \mathrm{~h}$ dietary recall interviews. The first dietary recall interview was collected in-person in the $\mathrm{MEC}^{15}$ while the second was collected by telephone 3-10 days later but never on the same day of the week as the MEC interview. ${ }^{16}$ Dietary interviews were conducted by trained interviewers using the validated $^{17-19}$ US Department of Agriculture Automated Multiple-Pass Method (AMPM). ${ }^{20}$ For children under 9 years of age, the interview was conducted with a proxy; for children between 6 and 8 years of age, in the presence of the child. Children aged 9-11 years provided their own data assisted by an adult household member (assistant). The preferred proxy/assistant was the most knowledgeable person about the child's consumption on the day before the interview. If the child had more than one caregiver, several individuals could contribute to the intake data. ${ }^{15} 16$

Among the 13272 people screened in NHANES 2009-2010, $10537(79.4 \%)$ participated in the household interview and $10253(77.3 \%)$ also participated in the MEC health examination. ${ }^{21}$ Of these, 9754 individuals provided 1 day of complete dietary intakes, of which 8406 provided 2 days. ${ }^{22}$

We evaluated 9317 survey participants aged 1 year and above who had 1 day $24 \mathrm{~h}$ dietary recall data and had not been breast fed on either of the 2 days. These individuals had similar sociodemographic characteristics (gender, age, race/ethnicity, family income and educational attainment) to the full sample of 10109 interviewed participants aged 1 year and above.

\section{Food classification according to processing}

We classified all recorded food items (N=280 132 Food Codes for both recall days) according to NOVA, a food classification based on the extent and purpose of industrial food processing. ${ }^{23-25}$ This classification includes four groups: 'unprocessed or minimally processed foods' (such as fresh, dry or frozen fruits or vegetables, grains, legumes, meat, fish and milk); 'processed culinary ingredients' (including table sugar, oils, fats, salt, and other substances extracted from foods or from nature, and used in kitchens to make culinary preparations); "processed foods' (foods manufactured with the addition of salt or sugar or other substances of culinary use to unprocessed or minimally processed foods, such as canned food and simple breads and cheese) and 'ultraprocessed foods' (formulations of several ingredients which, besides salt, sugar, oils and fats, include food substances not used in culinary preparations, in particular, flavours, colours, sweeteners, emulsifiers and other additives used to imitate sensorial qualities of unprocessed or minimally processed foods and their culinary preparations or to disguise undesirable qualities of the final product). A detailed definition of each food group and examples of food items classified in each group are shown in online supplementary table S1. The rationale underlying the classification is described elsewhere. ${ }^{26-29}$

For all food items (Food Codes) judged to be a handmade recipe, the classification was applied to the underlying ingredients (Standard Reference Codes -SR 
Codes-) obtained from the United States Department of Agriculture (USDA) Food and Nutrient Database for Dietary Studies (FNDDS) 5.0. ${ }^{30}$ Refer to online supplementary material (OSM) for further details.

\section{Assessing energy and added sugar contents}

For this study, we used Food Code energy values as provided by NHANES.

For handmade recipes, we calculated the underlying ingredient (SR Code) energy values using variables from both FNDDS $5.0^{30}$ and USDA National Nutrient Database for Standard Reference, Release 24 (SR24). ${ }^{31}$ Refer to OSM for further details.

Data on added sugars per Food Code and per SR Code were obtained by merging the Food Patterns Equivalents Database (FPED) 2009-2010 and the Food Patterns Equivalents Ingredients Database (FPID) 2009$2010 .{ }^{32}$ Added sugars are defined in these databases as "sugars that are added to foods as an ingredient during preparation, processing, or at the table. Added sugars do not include naturally occurring sugars (eg, lactose in milk, fructose in fruits). Examples of added sugars include brown sugar, cane sugar, confectioners' sugar, granulated sugar, dextrose, white sugar, corn syrup and corn syrup solids, molasses, honey, and all types of syrups such as maple syrup, table syrups, and pancake syrup." 32 These two databases express the content of added sugars in teaspoons per $100 \mathrm{~g}$. Teaspoons were converted into grams using the factor $4.2 \mathrm{~g}$ /teaspoon and into kcal using the factor $3.87 \mathrm{kcal} / \mathrm{g}$.

\section{Data analysis}

We utilised all available day 1 dietary data for each participant. Food items were sorted into mutually exclusive food subgroups within unprocessed or minimally processed foods $(\mathrm{n}=11)$, processed culinary ingredients $(\mathrm{n}=4)$, processed foods $(\mathrm{n}=4)$ and ultra-processed foods $(\mathrm{n}=18)$, as shown in table 1 . First, we evaluated the contributions of each of the NOVA food groups and subgroups to total energy and to the energy from added sugars. Next, we calculated the average content of added sugars in the overall US diet and in fractions of this diet composed by each of the NOVA food groups and subgroups. We also calculated the dietary content of added sugars in the group of unprocessed or minimally processed foods combined with the group of processed culinary ingredients, as foods belonging to these two groups are usually combined together in culinary preparations and therefore consumed together.

We used Gaussian regression to estimate the association between the dietary contribution of ultraprocessed foods and the dietary content of added sugars, each expressed as proportions of total energy. This association was also explored after adjusting for the proportion of added sugars in non-ultra-processed energy intake. The dietary contribution of ultraprocessed foods was transformed using restricted cubic spline functions to allow for non-linearity.
The average content of added sugars in the overall diet was compared across quintiles of the dietary contribution of ultra-processed foods. Poisson regression was used to assess whether the percentage of diets with more than $10 \%$ or $20 \%$ of total energy from added sugars increased across quintiles. This increase was also evaluated across demographic subgroups in stratified analysis. Tests of linear trend were performed in order to evaluate the effect of quintiles as a single continuous variable.

All regression models were adjusted for age (1-5, 6$11,12-19,20-39,40-59,60+$ years), sex, race/ethnicity (Mexican-American, Other Hispanic, Non-Hispanic white, Non-Hispanic black, Other race including Multi-racial), ratio of family income to poverty (categorised on the basis of Supplemental Nutrition Assistance Program (SNAP) eligibility as 0.00-1.30, $>1.30-3.50$ and $>3.50$ and above $)^{14}$ and educational attainment of respondents, for participants aged 20+ years, and of household reference persons otherwise $(<12,12$ and $>12$ years). Since 908 participants had missing values on family income and/or educational attainment, multivariable-adjusted analysis included 8409 individuals. The analysis which also adjusted for the added sugar content of all non-ultra-processed foods grouped together included 8335 individuals.

The NHANES sample weights were used in all analyses to account for differential probabilities of selection for the individual domains, non-response to survey instruments, and differences between the final sample and the total US population. The Taylor series linearisation variance approximation procedure was used for variance estimation in all analysis in order to account for the complex sample design and the sample weights. ${ }^{14}$

To minimise chance findings from multiple comparisons, statistical hypotheses were tested using a two tailed $\mathrm{p}<0.001$ level of significance. Data were analysed using Stata statistical software package V.12.1.

\section{RESULTS}

\section{Distribution of total energy intake by food groups}

The average US daily energy intake in 2009-2010 was $2069.5 \mathrm{kcal}$, and nearly three in five calories $(57.9 \%)$ came from ultra-processed foods (table 1).

Unprocessed or minimally processed foods contributed $29.6 \%$ of total calories, processed foods an additional $9.4 \%$, and processed culinary ingredients the remaining $2.9 \%$. The most common ultra-processed foods in terms of energy contribution were breads; soft drinks, fruit drinks and milk-based drinks; cakes, cookies and pies; salty snacks; frozen and shelf-stable plates; pizza and breakfast cereals. Meat, fruit and milk provided the most calories among unprocessed or minimally processed foods; ham and cheese, the most calories among processed foods; and table sugar and plant oils, the most calories among processed culinary ingredients. 
Table 1 Distribution of the total energy intake and of the energy intake from added sugars according to food groups, and the mean content of added sugars of each food group

\begin{tabular}{|c|c|c|c|c|c|}
\hline \multirow[b]{2}{*}{ Food groups } & \multicolumn{2}{|c|}{ Mean energy intake } & \multicolumn{2}{|c|}{$\begin{array}{l}\text { Mean energy intake from } \\
\text { added sugars }\end{array}$} & \multirow{2}{*}{$\begin{array}{l}\text { Mean content of } \\
\text { added sugars } \\
\text { Percentage of } \\
\text { energy from } \\
\text { added sugars }\end{array}$} \\
\hline & $\begin{array}{l}\text { Absolute } \\
\text { (kcal/day) }\end{array}$ & $\begin{array}{l}\text { Relative } \\
\text { (\% of total } \\
\text { energy intake) }\end{array}$ & $\begin{array}{l}\text { Absolute } \\
\text { (kcal/day) }\end{array}$ & $\begin{array}{l}\text { Relative (\% of total } \\
\text { energy intake from } \\
\text { added sugars) }\end{array}$ & \\
\hline Unprocessed or minimally processed foods & 585.5 & 29.6 & 0.0 & 0.0 & 0.0 \\
\hline Meat (includes poultry) & 165.3 & 7.9 & 0.0 & 0.0 & 0.0 \\
\hline Fruit* & 97.5 & 5.2 & 0.0 & 0.0 & 0.0 \\
\hline Milk and plain yoghurt & 96.4 & 5.1 & 0.0 & 0.0 & 0.0 \\
\hline Grains & 53.3 & 2.8 & 0.0 & 0.0 & 0.0 \\
\hline Roots and tubers & 32.2 & 1.6 & 0.0 & 0.0 & 0.0 \\
\hline Eggs & 28.8 & 1.4 & 0.0 & 0.0 & 0.0 \\
\hline Pasta & 28.4 & 1.4 & 0.0 & 0.0 & 0.0 \\
\hline Legumes & 16.2 & 0.8 & 0.0 & 0.0 & 0.0 \\
\hline Fish and sea food & 17.2 & 0.8 & 0.0 & 0.0 & 0.0 \\
\hline Vegetables & 13.5 & 0.7 & 0.0 & 0.0 & 0.0 \\
\hline Other unprocessed or minimally processed foods $†$ & 36.7 & 1.8 & 0.0 & 0.0 & 0.0 \\
\hline Processed culinary ingredients & 64.3 & 2.9 & 24.4 & 8.7 & 38.8 \\
\hline Table sugarł & 24.7 & 1.1 & 24.4 & 8.7 & 98.5 \\
\hline Plant oils & 27.5 & 1.3 & 0.0 & 0.0 & 0.0 \\
\hline Animal fats§ & 11.2 & 0.5 & 0.0 & 0.0 & 0.0 \\
\hline Other processed culinary ingredients & 0.9 & 0.04 & 0.0 & 0.0 & 0.0 \\
\hline $\begin{array}{l}\text { Unprocessed or minimally processed foods+processed } \\
\text { culinary ingredients }\end{array}$ & 649.8 & 32.6 & 24.4 & 8.7 & 3.7 \\
\hline Processed foods & 209.7 & 9.4 & 2.5 & 1.6 & 2.4 \\
\hline Cheese & 80.1 & 3.7 & 0.0 & 0.0 & 0.0 \\
\hline Ham and other salted, smoked or canned meat or fish & 26.4 & 1.2 & 0.3 & 0.2 & 1.4 \\
\hline Vegetables and other plant foods preserved in brine & 13.4 & 0.7 & 1.6 & 0.9 & 13.7 \\
\hline Other processed foods ${ }^{* *}$ & 89.8 & 3.8 & 0.6 & 0.5 & 1.2 \\
\hline Ultra-processed foods & 1209.8 & 57.9 & 265.2 & 89.7 & 21.1 \\
\hline Breads & 191.6 & 9.5 & 10.6 & 7.6 & 5.7 \\
\hline Cakes, cookies and pies & 122.8 & 5.7 & 29.8 & 11.2 & 24.2 \\
\hline Salty snacks & 93.2 & 4.6 & 1.2 & 0.7 & 1.4 \\
\hline Frozen and shelf-stable plate meals & 80.6 & 4.02 & 1.1 & 0.7 & 1.6 \\
\hline Soft drinks, carbonated & 81.8 & 3.7 & 75.2 & 17.1 & 69.9 \\
\hline Pizza (ready-to-eat/heat) & 81.8 & 3.5 & 2.4 & 1.4 & 2.9 \\
\hline Fruit drinksł‡ & 69.2 & 3.3 & 55.7 & 13.9 & 67.5 \\
\hline Breakfast cereals & 50.9 & 2.8 & 12.4 & 6.4 & 23.3 \\
\hline Sauces, dressings and gravies & 49.8 & 2.4 & 4.4 & 2.8 & 10.0 \\
\hline Reconstituted meat or fish products & 51.5 & 2.4 & 0.7 & 0.6 & 2.0 \\
\hline Sweet snacks & 50.9 & 2.4 & 19.4 & 7.1 & 38.9 \\
\hline Ice cream and ice pops & 48.7 & 2.3 & 18.3 & 5.9 & 36.9 \\
\hline Milk-based drinks§§ & 34.6 & 1.8 & 10.8 & 4.6 & 34.1 \\
\hline Dessertsๆी & 36.4 & 1.8 & 18.5 & 7.3 & 48.5 \\
\hline French fries and other potato products & 37.8 & 1.7 & 0.0 & 0.0 & 0.0 \\
\hline Sandwiches and hamburgers on bun (ready-to-eat/heat) & 32.5 & 1.4 & 1.3 & 0.6 & 4.4 \\
\hline Instant and canned soups & 14.3 & 0.8 & 0.1 & 0.1 & 0.7 \\
\hline Other ultra-processed foods $† \dagger \dagger$ & 81.5 & 3.8 & 3.1 & 1.5 & 7.8 \\
\hline Total & 2069.5 & 100.0 & 292.2 & 100.0 & 13.8 \\
\hline
\end{tabular}

US population aged 1+ years (National Health and Nutrition Examination Survey 2009-2010) (N=9317).

*Including freshly squeezed juices.

tIncluding nuts and seeds (unsalted); yeast; dried fruits (without added sugars) and vegetables; non presweetened, non-whitened,

non-flavoured coffee and tea; coconut water and meat; homemade soup and sauces; flours; tapioca.

łncluding honey, molasses, maple syrup (100\%).

§Including butter, lard and cream.

ףIncluding starches; coconut and milk cream; unsweetened baking chocolate, cocoa powder and gelatin powder; vinegar; baking powder and baking soda.

**Including salted or sugared nuts and seeds; peanut, sesame, cashew and almond butter or spread; beer and wine.

¥¥Including fruit and fruit-flavoured, non-carbonated and other sweetened drinks, including presweetened tea and coffee, energy drinks, sports drinks with no milk added, non-alcoholic wine.

$\S \S$ Including flavoured yogurt sweetened with sugar or with low-calorie sweetener, milkshake.

१ๆ IIncluding ready-to-eat and dry-mix desserts such as pudding.

t†tIncluding soya products such as meatless patties and fish sticks; baby food and baby formula; dips, spreads, mustard and catsup; margarine; sugar substitutes, sweeteners and all syrups (excluding 100\% maple syrup); distilled alcoholic drinks. 
Distribution of energy intake from added sugars by food groups

The average US daily intake of added sugars was $292.2 \mathrm{kcal}$ (table 1). Notably, almost $90 \%$ of this $(89.7 \%$ ) came from ultra-processed foods. The main sources of added sugars among ultra-processed foods were: soft drinks $(17.1 \%$ of US intake of added sugars); fruit drinks (13.9\%); milk-based drinks (4.6\%); cakes, cookies and pies $(11.2 \%)$; breads $(7.6 \%)$; desserts $(7.3 \%)$; sweet snacks $(7.1 \%)$; breakfast cereals $(6.4 \%)$; and ice creams and ice pops $(5.9 \%)$. In contrast, only $8.7 \%$ of the added sugars in the US diet came from processed culinary ingredients (table sugar consumed as part of dishes or drinks prepared from scratch by consumers or a cook), and only $1.6 \%$ from processed foods.

The average content of added sugars in ultraprocessed foods (21.1\% of calories) was eightfold higher than in processed foods $(2.4 \%)$ and fivefold higher than in unprocessed or minimally processed foods and processed culinary ingredients grouped together $(3.7 \%)$ (table 1).

\section{Association between consumption of ultra-processed foods} and added sugar intake

In unadjusted restricted cubic splines Gaussian regression analysis, a strong linear association was identified between the dietary contribution (percentage of calories) of ultra-processed foods and the dietary content (percentage of calories) in added sugars (coefficient for linear term $=0.20,95 \%$ CI 0.17 to 0.23 ) (figure 1 ).

There was little evidence of non-linearity in the restricted cubic spline model (Wald test for linear term

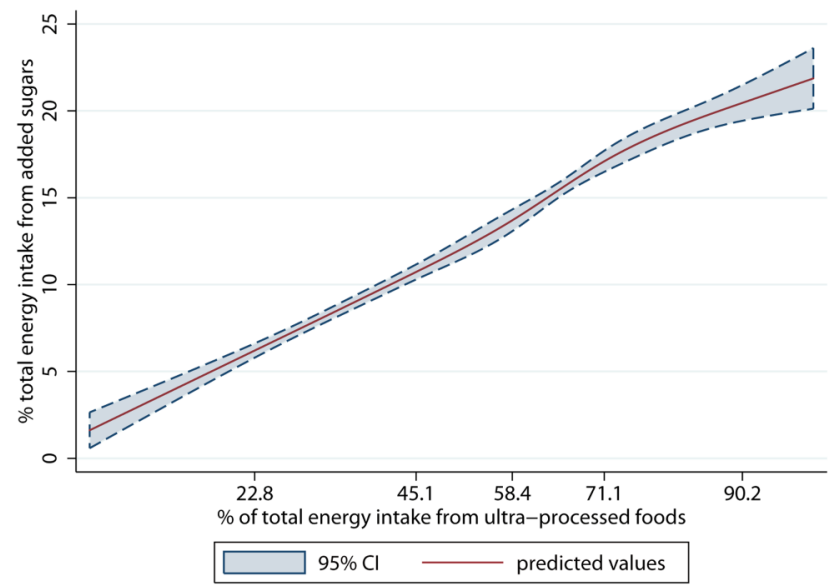

Figure 1 The dietary content in added sugars regressed on the dietary contribution of ultra-processed foods evaluated by restricted cubic splines. US population aged 1+ years (National Health and Nutrition Examination Survey 20092010) $(N=9317)$. The values shown on the $x$-axis correspond to the 5th, 27.5th, 50th, 72.5th, and 95th centiles for percentage of total energy from ultra-processed foods (knots). Coefficient for linear term $=0.20(95 \% \mathrm{Cl} 0.17$ to 0.23$)$. There was little evidence of non-linearity in the restricted cubic spline model (Wald test for linear term $p<0.0001$; Wald test for all non-linear terms $\mathrm{p}=0.27$ ). $\mathrm{p}<0.0001$; Wald test for all non-linear terms $\mathrm{p}=0.27$ ). The strength of the association remained fairly the same after adjusting for age, sex, race/ethnicity, family income, educational attainment and proportion of added sugars in non-ultra-processed energy intake (coefficient for linear term $=0.19$, 95\% CI 0.17 to 0.22 ). Overall, each increase in 5 percentage points of energy in consumption of ultra-processed foods was associated with 1 higher percentage point of energy in the consumption of added sugars.

Across quintiles of energy-adjusted ultra-processed food consumption, the intake of added sugars increased substantially and monotonically from $7.5 \%$ of total calories in the lowest quintile to $19.5 \%$ in the highest quintile. Across the same quintiles, the proportion of individuals consuming more than $10 \%$ of total energy from added sugars (59.6\% in the total population) increased from $26.4 \%$ to $82.1 \%$, respectively. An even more pronounced increase was seen in the proportion of individuals consuming more than $20 \%$ of their total energy from added sugars: from $4.7 \%$ in the lowest quintile to $41.2 \%$ in the highest quintile (table 2). Similar increases were seen in stratified analysis by major demographic subgroups (see online supplementary table S2). The magnitude and the statistical significance of the association between the dietary contribution of ultraprocessed foods and the dietary content in added sugars did not change with adjustment for sex, age, race/ethnicity, family income and educational attainment.

\section{DISCUSSION}

In this analysis of nationally representative data, we confirmed the excessive consumption of added sugars in the USA. ${ }^{10} 11$ We also provide new evidence that ultraprocessed foods represent more than half of all calories in the US diet, and contribute nearly $90 \%$ of all added sugars. Added sugars represented 1 of every 5 calories in the average ultra-processed food $(21.1 \%)$, far higher than the content of added sugars in processed foods $(2.4 \%)$ and in unprocessed or minimally processed foods, and processed culinary ingredients grouped together $(3.7 \%)$. A strong linear relationship was found between the dietary contribution of ultra-processed foods and the dietary content of added sugars. Moreover, the risk of exceeding the recommended upper limit of $10 \%$ energy from added sugars was far higher when ultra-processed food consumption was high, and risk differences were even more pronounced for exceeding a limit of $20 \%$ energy. Notably, only those Americans in the lowest quintile of ultra-processed food consumption met the recommended limit of $<10 \%$ energy from added sugars. To the best of our knowledge, this is the first study to assess the consumption of ultra-processed foods and establish its relationship with excessive added sugar intake in the USA.

The high consumption of added sugars in the USA is most likely contributing to excess obesity, type 2 
Table 2 Indicators of the dietary content in added sugars according to the dietary contribution of ultra-processed foods

\begin{tabular}{|c|c|c|c|c|c|c|c|c|}
\hline \multirow{2}{*}{\multicolumn{2}{|c|}{$\begin{array}{l}\text { Dietary contribution of } \\
\text { ultra-processed foods } \\
\text { (\% of total energy intake) }\end{array}$}} & \multirow{3}{*}{$\begin{array}{l}\text { Percentage of } \\
\text { total energy } \\
\text { intake from } \\
\text { added sugars } \\
\text { Mean }\end{array}$} & \multicolumn{6}{|c|}{ Indicators } \\
\hline & & & \multicolumn{3}{|c|}{$\begin{array}{l}\text { Participants with more than } \\
10 \% \text { of total energy intake } \\
\text { from added sugars }\end{array}$} & \multicolumn{3}{|c|}{$\begin{array}{l}\text { Participants with more than } \\
20 \% \text { of total energy intake } \\
\text { from added sugars }\end{array}$} \\
\hline Quintiles & Mean (range) & & Per cent & $\mathbf{P R}^{*}$ & PRadj† & Per cent & $\mathbf{P R}^{*}$ & PRadj† \\
\hline 1st $(n=1937)$ & 28.9 (0 to 40.1$)$ & 7.5 & 26.4 & 1 & 1 & 4.7 & 1 & 1 \\
\hline 2nd $(n=1888)$ & 47.3 (40.1 to 53.3 ) & 11.1 & 50 & 1.9 & 1.9 & 10.5 & 2.2 & 2.2 \\
\hline $3 r d(n=1814)$ & 58.7 (53.3 to 64.1$)$ & 13.8 & 62.7 & 2.4 & 2.3 & 21.1 & 4.5 & 4.3 \\
\hline 4th $(n=1779)$ & 69.7 (64.1 to 75.7$)$ & 16.9 & 76.6 & 2.9 & 2.8 & 29.9 & 6.4 & 5.9 \\
\hline 5th $(n=1899)$ & 85.1 (75.7 to 100$)$ & $19.5 \ddagger$ & 82.1 & $3.1 \ddagger$ & $2.9 \ddagger$ & 41.2 & $8.8 \ddagger$ & $7.9 \ddagger$ \\
\hline Total $(n=9317)$ & 57.9 (0 to 100.0) & 13.8 & 59.6 & _ & - & 21.5 & - & - \\
\hline
\end{tabular}

US population aged 1+ years (National Health and Nutrition Examination Survey 2009-2010).

${ }^{*} \mathrm{PR}=$ Prevalence ratios estimated using Poisson regression $(\mathrm{N}=9317)$.

†PRadj=Prevalence ratios adjusted for sex, age groups, race/ethnicity, ratio of family income to poverty and educational attainment, as above ( $\mathrm{N}=8409)$.

¥Significant linear trend across all quintiles $(p \leq 0.001)$, both in unadjusted models and models adjusted for sex, age group (1-5, 6-11, 12-19, 20-39, 40-59, 60+ years), race/ethnicity (Mexican-American, Other Hispanic, Non-Hispanic white, Non-Hispanic black and Other raceincluding Multiracial), ratio of family income to poverty (Supplemental Nutrition Assistance Program $0.00-1.30,>1.30-3.50$ and $>3.50$ and over) and educational attainment $(<12,12$ and $>12$ years).

diabetes, dyslipidaemia, hypertension and coronary heart disease. ${ }^{13-5}$ Consequently, most dietary guidelines now recommend limiting added sugar consumption. However, such guidelines are not always clear on how to put this recommendation into practice. Our study suggests that in the USA, limiting the consumption of ultraprocessed foods may be a highly effective way to decrease added sugars. A reduction in ultra-processed foods should also increase the intake of more healthful, minimally processed foods such as milk, fruits and nuts, and freshly prepared dishes based on whole grains and vegetables, which would produce additional health benefits beyond the reduction in added sugar. Consistent with this approach, in Brazil, where the consumption of added sugars is as high as in the USA, ${ }^{33}$ the new dietary guidelines launched in 2014 emphasise the importance of not replacing unprocessed or minimally processed foods and freshly prepared dishes by ultra-processed foods. ${ }^{34}$

Few studies have assessed the impact of levels of food processing on the nutrient profile of the US diet. One analysis using data from NHANES $2003-2008^{35}$ used a food classification system ${ }^{36}$ including 'Mixtures of combined Ingredients' and 'Ready-to-eat', which are mostly ultra-processed foods, and together contributed to about half of the total energy intake and three-quarters of energy intake from added sugars. Another study evaluated household barcoded purchasing data from 2000 to 2012 using a classification system guided by the one used in our study. ${ }^{37}$ In 2012, the mean per capita purchase of 'highly processed foods', a category similar to ultra-processed foods, corresponded to $61.0 \%$ of all calories and had higher adjusted median total sugar content than 'less processed foods'. This report did not evaluate added sugars nor the contribution of processed foods to sugar intake. It also did not capture non-barcoded items such as unpackaged fresh fruit, vegetables and meat, or highly processed foods such as ready-to-eat store-prepared items. An investigation in Canada, using 2001 household purchasing data, found that ultra-processed foods are high in free sugars and that only households in the lowest quintile of ultra-processed food purchasing might have met the recommended limit of $<10 \%$ energy from free sugars $(9.2 \%) .{ }^{38}$ Being based on household purchasing data, these two prior studies and others based on the NOVA classification system ${ }^{23} 39-42$ could not evaluate the fraction of wasted food nor purchases at restaurants, which represent a substantial proportion of US calories. Our findings build on and considerably extend these prior reports by evaluating food processing and added sugar intake using contemporary, nationally representative dietary intake data in the USA.

Our study has several strengths. We studied a large, nationally representative sample of the US population, increasing generalisability. Use of data on added sugars, rather than total sugars or sugar-sweetened beverages, corresponds to the relevant area of prioritisation of recent national and international guidelines. Our investigation was based on individual consumption data, rather than market disappearance or household purchasing data which cannot account for differences between amounts purchased and amounts actually consumed.

Potential limitations should be considered. As with most population measures, dietary data obtained by $24 \mathrm{~h}$ recalls are imperfect. However, the standardised methods and approach of NHANES minimise potential error and bias, particularly for assessing population averages as focused on in the present study. Previous studies suggest that people with obesity may underreport consumption of foods with caloric sweeteners ${ }^{43}$ such as desserts and sweet baked goods. ${ }^{44} 45$ If so, these 
biases may lead to an underestimation of the dietary contribution of ultra-processed foods and the overall intake of added sugars, but should have much less effect on the association between these. Although NHANES collects some information indicative of food processing (ie, place of meals, product brands), these data are not consistently determined for all food items, which could lead to modest overestimation or underestimation of the consumption of ultra-processed foods.

In conclusion, we found that ultra-processed foods contribute almost $60 \%$ of calories and $90 \%$ of added sugars consumed in the USA. Only Americans in the lowest quintile of ultra-processed food consumption met the recommended guidelines for intake of added sugars. Decreasing the consumption of ultra-processed foods could be an effective way of reducing the excessive intake of added sugars in the USA.

Contributors CAM, EMS and DM designed the research. EMS, LGB and MLdCL took care of data management. EMS, J-CM and MLdCL analysed the data. EMS, DM and CAM wrote the paper. CAM and EMS had primary responsibility for the final content. All the authors read and approved the final manuscript. All the authors had full access to all of the data (including statistical reports and tables) in the study and can take responsibility for the integrity of the data and the accuracy of the data analysis.

Funding This research received funding from Conselho Nacional de Desenvolvimento Científico e Tecnológico, Edital MCTI/CNPq/Universal 14/2014.

Competing interests DM reports ad hoc honoraria or consulting from Bunge, Haas Avocado Board, Nutrition Impact, Amarin, Astra Zeneca, Boston Heart Diagnostics, GOED, and Life Sciences Research Organisation; and scientific advisory boards, Unilever North America and Elysium Health.

Provenance and peer review Not commissioned; externally peer reviewed.

Data sharing statement No additional data are available.

Open Access This is an Open Access article distributed in accordance with the Creative Commons Attribution Non Commercial (CC BY-NC 4.0) license, which permits others to distribute, remix, adapt, build upon this work noncommercially, and license their derivative works on different terms, provided the original work is properly cited and the use is non-commercial. See: http:// creativecommons.org/licenses/by-nc/4.0/

\section{REFERENCES}

1. Guideline: sugars intake for adults and children. Geneva: World Health Organization, 2015.

2. NHS Health Choices. Eight tips for healthy eating. http://www.nhs. uk/Livewell/Goodfood/Pages/eight-tips-healthy-eating.aspx (accessed Aug 2015).

3. Canadian Heart and Stroke Foundation Position Statement, August 2014. http://www.heartandstroke.com/site/c.ikIQLcMWJtE/ b.9201361/k.47CB/Sugar_heart_disease_and_stroke.htm (accessed Aug 2015).

4. Johnson RK, Appel LJ, Brands M, et al. American Heart Association Nutrition Committee of the Council on Nutrition, Physical Activity, and Metabolism and the Council on Epidemiology and Prevention. Dietary sugars intake and cardiovascular health: a scientific statement from the American Heart Association. Circulation 2009;120:1011-20.

5. Scientific Report of the 2015 Dietary Guidelines Advisory Committee. http://www.health.gov/dietaryguidelines/2015-scientificreport/PDFs/Scientific-Report-of-the-2015-Dietary-GuidelinesAdvisory-Committee.pdf

6. US Department of Agriculture and US Department of health and human services. Dietary guidelines for Americans, 2010. 7th edn, Washington DC: US Government Printing Office, December, 2010.
7. Marriott BP, Olsho L, Hadden L, et al. Intake of added sugars and selected nutrients in the United States, National Health and Nutrition Examination Survey (NHANES) 2003-2006. Crit Rev Food Sci Nutr 2010;50:228-58.

8. Bowman SA. Diets of individuals based on energy intakes from added sugars. Fam Econ Nutr Rev 1999;12:31-8.

9. Murphy $\mathrm{S}$, Johnson $\mathrm{R}$. The scientific basis of recent US guidance on sugars intake. Am J Clin Nutr 2003;78:827S-33S.

10. Welsh JA, Sharma AJ, Grellinger L, et al. Consumption of added sugars is decreasing in the United States. Am J Clin Nutr 2011;94:726-34.

11. Yang Q, Zhang Z, Gregg EW, et al. Added sugar intake and cardiovascular diseases mortality among US adults. JAMA Intern Med 2014;174:516-24.

12. United States Department of Agriculture. Economic Research Service. Sugar and Sweeteners Yearbook Tables. http://www.ers. usda.gov/data-products/sugar-and-sweeteners-yearbook-tables.aspx (accessed Aug 2015).

13. National Health and Nutrition Examination Survey http://wwwn.cdc. gov/nchs/nhanes/search/nhanes09_10.aspx (accessed Aug 2015).

14. Johnson CL, Paulose-Ram R, Ogden CL, et al. National health and nutrition examination survey: analytic guidelines, 1999-2010. Vital Health Stat 2. 2013;1-24. http://www.cdc.gov/nchs/data/series/sr_ 02/sr02_161.pdf (accessed Aug 2015)

15. NHANES. MEC In-Person Dietary Interviewers Procedures Manual. January 2009. http://www.cdc.gov/nchs/data/nhanes/nhanes_09_10/ Dietarylnterviewers_Inperson.pdf (accessed Aug 2015).

16. NHANES. Phone Follow-Up Dietary Interviewer Procedures Manual. September 2009. http://www.cdc.gov/nchs/data/nhanes/nhanes_09_ 10/Dietary_PFU_09.pdf (accessed Aug 2015).

17. Moshfegh AJ, Rhodes DG, Baer DJ, et al. The USDA Automated Multiple-Pass Method reduces bias in the collection of energy intakes. Am J Clin Nutr 2008;88:324-32.

18. Blanton CA, Moshfegh AJ, Baer DJ, et al. The USDA Automated Multiple-Pass Method accurately estimates group total energy and nutrient intake. J Nutr 2006;136:2594-9.

19. Rumpler WV, Kramer M, Rhodes DG, et al. Identifying sources of reporting error using measured food intake. Eur J Clin Nutr 2008;62:544-52.

20. Automated Multiple-Pass Method. United States Department of Agriculture. Agriculture Research Service. http://www.ars.usda.gov/ ba/bhnrc/fsrg (accessed Aug 2015).

21. National Health and Nutrition Examination Survey. NHANES Response Rates and Population Totals. Response Rates. http:// www.cdc.gov/nchs/nhanes/response_rates_CPS.htm (accessed Aug 2015).

22. National Health and Nutrition Examination Survey. 2009-2010 Data Documentation, Codebook, and Frequencies. http://www.cdc.gov/ nchs/nhanes/nhanes2009-2010/DR1IFF_F.htm (accessed Aug 2015).

23. Monteiro CA, Levy RB, Claro RM, et al. A new classification of foods based on the extent and purpose of their processing. Cad Saúde Pública 2010;26:2039-49.

24. Moubarac JC, Parra DC, Cannon G, et al. Food Classification Systems Based on Food Processing: significance and implications for policies and actions: a systematic literature review and assessment. Curr Obes Rep 2014;3:256-72.

25. Monteiro CA, Cannon G, Levy RB, et al. Ultra-processing and a new classification of foods. In: Neff R, ed. Introduction to US food system. Public health, environment, and equity. San Francisco: Jossey Bass A Wiley Brand, 2015:338-9.

26. Monteiro CA. Nutrition and health. The issue is not food, nor nutrients, so much as processing. Public Health Nutr 2009;12:729-31.

27. Ludwig DS. Technology, diet, and the burden of chronic disease. JAMA 2011;305:1352-3.

28. Monteiro CA, Cannon G, Levy RB, et al. The Food System. Processing. The big issue for disease, good health, well-being. World Nutr 2012;3:527-69. http://www.wphna.org (accessed Aug 2015).

29. Moodie R, Stuckler D, Monteiro C, et al. Profits and pandemics: prevention of harmful effects of tobacco, alcohol, and ultra-processed food and drink industries. Lancet 2013;381:670-9.

30. Ahuja JKA, Montville JB, Omolewa-Tomobi G, et al. USDA food and nutrient database for dietary studies, 5.0. US Beltsville, MD: Department of Agriculture, Agricultural Research Service, Food Surveys Research Group, 2012.

31. US Department of Agriculture, Agricultural Research Service. 2011. USDA National Nutrient Database for Standard Reference, Release 24. Nutrient Data Laboratory Home Page. http://www.ars.usda.gov/ ba/bhnrc/ndl (accessed Aug 2015).

32. Bowman SA, Clemens JC, Thoerig RC, et al. Food patterns equivalents database 2009-10: methodology and user guide 
[Online]. Food surveys research group, beltsville human nutrition research center, agricultural research service, US Beltsville, Maryland: Department of Agriculture, 2013. http://www.ars.usda.gov/ $\mathrm{ba/bhnrc/fsrg} \mathrm{(accessed} \mathrm{Jun} \mathrm{2013).}$

33. da Costa Louzada ML, Bortoletto Martins AP, Silva Canella D, et al. Ultra-processed foods and dietary quality in Brazil. Rev Saude Publica 2015;49:38.

34. Dietary Guidelines for the Brazilian Population. 2nd edn. Ministry of Health of Brazil, 2014.

35. Eicher-Miller HA, Fulgoni VL III, Keast DR. Contributions of processed foods to dietary intake in the US from 2003-2008: a report of the Food and Nutrition Science Solutions Joint Task Force of the Academy of Nutrition and Dietetics, American Society for Nutrition, Institute of Food Technologists, and International Food Information Council. J. Nutr 2012;142:2065S-72S.

36. International Food Information Council Foundation. Understanding our food communications tool kit, 2010. http://www.foodinsight.org/ For-Professionals/Understanding-Our-Food/tabid/1398/Default.aspx (accessed Aug 2015).

37. Poti JM, Mendez MA, Ng SW, et al. Is the degree of food processing and convenience linked with the nutritional quality of foods purchased by US households? Am J Clin Nutr 2015:101:1251-62.

38. Moubarac JC, Martins AP, Claro RM, et al. Consumption of ultra-processed foods and likely impact on human health. Evidence from Canada. Public Health Nutr 2013;16:2240-8.
39. Monteiro CA, Levy RB, Claro RM, et al. Increasing consumption of ultra-processed foods and likely impact on human health: evidence from Brazil. Public Health Nutr 2011;14:5-13

40. Crovetto MM, Uauy R, Martins AP, et al. [Household availability of ready-to-consume food and drink products in Chile: impact on nutritional quality of the diet]. Rev Med Chil 2014;142:850-8.

41. Monteiro CA, Moubarac JC, Cannon G, et al. Ultra-processed products are becoming dominant in the global food system. Obes Rev 2013;14(Suppl 2):21-8.

42. Canella DS, Levy RB, Martins AP, et al. Ultra-processed food products and obesity in Brazilian households (2008-2009). PLoS ONE 2014;9:e92752.

43. Bingham S, Luben $\mathrm{R}$, Welch $\mathrm{A}$, et al. Epidemiologic assessment of sugars consumption using biomarkers: comparisons of obese and nonobese individuals in the European prospective investigation of cancer Norfolk. Cancer Epidemiol Biomarkers Prev 2007;16: 1651-4.

44. Lafay L, Mennen L, Basdevant A, et al. Does energy intake underreporting involve all kinds of food or only specific food items? Results from the Fleurbaix Laventie Ville Santé (FLVS) study. Int $\mathrm{J}$ Obes Relat Metab Disord 2000;24:1500-6.

45. Pryer JA, Vrijheid M, Nichols R, et al. Who are the "low energy reporters" in the dietary and nutritional survey of British adults? Int $J$ Epidemiol 1997;26:146-54. 